Науковий вісник НлтУ України

Scientific Bulletin of UNFU

http://nv.nltu.edu.ua

https://doi.org/10.15421/40280223

Article received 23.03.2018 $\mathrm{p}$.

Article accepted 29.03.2018 p.

удк 538.9:536.6
ISSN 1994-7836 (print)

ISSN 2519-2477 (online)

(c) (1)

@ $\varangle$ Correspondence author

R. O. Navrodska

navrodska-ittf@ukr.net

Н. М. Фіалко ${ }^{1}$, Р. О. Навродська ${ }^{1}$, Р. В. Дінжсос ${ }^{2}$, С. І. Шевчук ${ }^{1}$

${ }^{1}$ Інститут технічної теплофізики НАН України, м. Київ, Украӥна

${ }^{2}$ Миколаївський національний університет ім. В. О. Сухомлинського, м. Миколаӥв, Украӥна

\title{
ВОДОГРІЙНІ КОНДЕНСАЦІЙНІ ТЕПЛОУТИЛІЗАТОРИ IЗ ЗАСТОСУВАННЯМ НАНОКОМПОЗИЦІЙНИХ МАТЕРІАЛІВ ДЛЯ ГАЗОСПОЖИВАЛЬНИХ ОПАЛЮВАЛЬНИХ КОТЛІВ
}

\begin{abstract}
Викладено результати досліджень ефективності використання в теплоутилізаційних технологіях газоспоживальних опалювальних котельних установок із глибоким охолодження їхніх відхідних газів водогрійного теплоутилізаційного устаткування різного типу. Розглянуто устаткування, теплообмінні поверхні якого компонувались 3 пучків поперечно-оребрених труб двох видів та гладкотрубних пучків. Визначено для різних режимів роботи котельних установок протягом опалювального періоду такі відносні характеристики даних поверхонь, як теплопродуктивність на одиницю маси цієї поверхні та ії об'єм на одиницю теплопродуктивності. Виконано порівняльний аналіз зазначених характеристик при використанні для поверхонь теплообміну традиційних матеріалів і полімерних мікро- і нанокомпозитів з різними коефіцієнтами теплопровідності. За значеннями робочих температур теплообмінної поверхні із мікро- і нанокомпозитів визначено іiї полімерну матрицю, а за величиною теплопровідності - необхідний склад наповнювачів полімеру, якими можуть слугувати мікрочастки алюмінію або вуглецеві нанотрубки. Показано, що для опалювальних котельних установок водогрійне теплоутилізаційне устаткування із вказаних нанокомпозиційних матеріалів за питомою теплопродуктивністю має істотні переваги над традиційно застосовуваними аналогами цього призначення.
\end{abstract}

Ключові слова: теплоутилізаційні технології; глибоке охолодження відхідних газів; полімерні мікро- і нанокомпозити; теплофізичні властивості; ефективність.

Вступ. В умовах дефіциту в Україні власних енергоресурсів, зокрема природного газу, актуальним є подальший розвиток енергоощадних технологій для котельних установок у комунальній теплоенергетиці (Dolinsky, et al., 2014; Zimin, et al., 2008; Fialko, et al., 2000, 2003). Підвищення ефективності використання палива в цих установках зазвичай реалізується шляхом утилізації теплоти відхідних газів. Широке впровадження в котельнях теплоутилізаційних технологій із глибоким охолодженням цих газів і використанням теплоти пароутворення стримується низкою проблем, пов'язаних здебільшого 3 недостатньою ефективністю устаткування систем теплоутилізації, його значними габаритами та вартістю, а також $з$ необхідністю захисту газовідвідних трактів та стокових комунікацій цих котелень від корозійного руйнування, спричиненого утворюваним під час глибокого охолодження газів кислим конденсатом (Fialko, et al., 2014).

Використання в теплоутилізаційних технологіях но- вих прогресивних матеріалів на основі полімерних мікpo- i нанокомпозитів (Kim, et al., 2016; Dinzhos, et al., 2014; Dolinskiy, et al., 2015a, 2015b), що характеризуються низкою унікальних властивостей у плані теплової ефективності, міцності та корозійної стійкості, дасть змогу значною мірою вирішити зазначені проблеми.

Мета дослідження полягає у теплофізичному обгрунтуванні використання полімерних мікро- і нанокомпозиційних матеріалів для виготовлення теплообмінних поверхонь водогрійного теплоутилізаційного устаткування котельних установок комунальної теплоенергетики.

Матеріал і методи дослідження. Дослідження виконували при використанні для котельних установок теплоутилізаційних технологій із глибоким охолодженням відхідних газів. Схему котельної установки, оснащеної відповідною системою теплоутилізації з використанням водогрійного устаткування, наведено на рис. 1. Димові гази від котла надходять у водогрійний

\section{Інформація про авторів:}

Фіалко Наталія Михайлівна, д-р техн. наук, професор, член-кореспондент НАН України, завідувач відділу. Email: nmfialko@ukr.net

Навродська Раїса Олександрівна, канд. техн. наук, ст. науковий співробітник, провідний науковий співробітник.

Email: navrodska-ittf@ukr.net

Дінжос Роман Володимирович, канд. фіз.-мат. наук, доцент. Email: dinzhosrv@gmail.com

Шевчук Світлана Іванівна, канд. техн. наук, ст. науковий співробітник. Email: s.i.shevchuk@gmail.com

Цитування за ДстУ: Фіалко Н. М., Навродська Р. О., Дінжос Р. В., Шевчук С. І. Водогрійні конденсаційні теплоутилізатори із застосуванням нанокомпозиційних матеріалів для газоспоживальних опалювальних котлів. Науковий вісник НлтУ України. 2018, т. 28, № 2. C. 124-128.

Citation APA: Fialko, N. M., Navrodska, R. O., Dinzhos, R. V., \& Shevchuk, S. I. (2018). Heating Condensation Heat-Outs with the Use of Nanocomposition Materials for Gas-Consuming Heating Boilers. Scientific Bulletin of UNFU, 28(2), 124-128. https://doi.org/10.15421/40280223 
теплоутилізатор 2, де охолоджуються при нагріванні зворотної тепломережної води системи теплопоста-

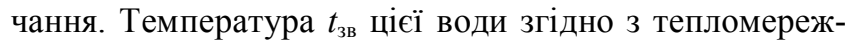
ним графіком зазвичай змінюється в межах $30-70{ }^{\circ} \mathrm{C}$, що відповідає режиму роботи котла в інтервалі температур $t_{\text {нс }}$ навколишнього середовища $-20-+8{ }^{\circ} \mathrm{C}$. $3 \mathrm{i}$ зменшенням температури $t_{3 в}<50{ }^{\circ} \mathrm{C}$ відбувається охолодження димових газів нижче від точки роси водяної пари, що міститься в газах, і конденсація частини цієї пари на теплообмінних поверхнях теплоутилізатора, тобто реалізується конденсаційний режим його роботи. Утворений конденсат для газового палива зазвичай має водневий показник $\mathrm{pH}$ в межах 5-6. 3 огляду на це, наведена теплоутилізаційна система для відвернення конденсатоутворення у газовідвідному тракті оснащується газопідігрівачем 3, в якому відбувається підсушування охолоджених в теплоутилізаторі димових газів шляхом їх підігрівання. Необхідний рівень цього підігрівання визначається умовами охолодження газів у відвідних каналах та димовій трубі 4. Утворений конденсат надходить до збірника 6 , а далі - систему відведення конденсату, яка може оснащатись нейтралізатором

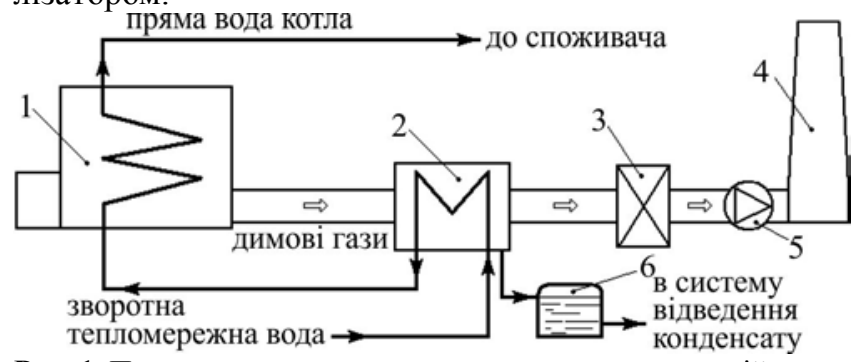

Рис. 1. Принципова схема котельної установки з водогрійним теплоутилізатором: 1) котел; 2) теплоутилізатор; 3) газопідігрівач; 4) димова труба; 5) димосос; 6) збірник конденсату

Перспективність використання полімерних мікро- і нанокомпозитів для виготовлення елементів теплоутилізаційних установок, що працюють в умовах впливу агресивного конденсату, пов'язана з підвищеною корозійною стійкістю цих композитів. Окрім цього, останні, маючи близькі теплопровідні властивості з традиційними аналогами - корозійностійкими сталями, можуть мати переваги над цими аналогами і за масогабаритними, ціновими показниками тощо.

У роботі виконано порівняльний аналіз основних характеристик водогрійних теплоутилізаторів із полімерних мікро- і нанокомпозитів та традиційних матеріалів. Характеристики теплообмінних поверхонь 3 полімерних мікро- і нанокомпозитів порівнювали з відповідними показниками для поверхонь, що зазвичай застосовують у таких ситуаціях. Ці зіставлення проводили за умови однакових теплогідравлічних режимів роботи теплообмінних апаратів, тобто за тих самих теплопродуктивностей, діапазонів робочих температур і тисків, витрат теплоносіїв тощо. При цьому порівняльний аналіз виконували в діапазоні зміни від 30 до 100 \% навантаження котла згідно 3 температурою навколишнього середовища $t_{\text {нс }}$ за тепломережним графіком 3 температурним перепадом 70-95 ${ }^{\circ} \mathrm{C}$. Теплопродуктивність котла, температура його відхідних газів та ККД, коефіцієнт надлишку повітря в номінальному режимі становили $2 \mathrm{MBT}, 160{ }^{\circ} \mathrm{C}, 92 \%$ та 1,1 відповідно. До того ж враховували, що за регламентом зі зменшенням навантаження котла до 50 \% відбувається його переведення в номі- нальний режим роботи 3 подальшим зниженням наван-

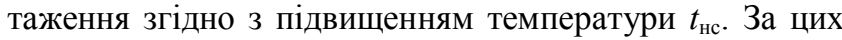
умов у котельні відповідно зменшується кількість котлів, що працюють.

Основними показниками для порівняння ефективності теплообмінних поверхонь слугували: питома теплопродуктивність $Q^{*}$ (теплопродуктивність на одиницю маси вказаної поверхні) та відносний об'єм $V^{*}$ (об'єм поверхні на одиницю утилізованої теплоподуктивності). Ця теплопродуктивність $Q^{*}$ характеризує теплову ефективність водонагрівача, а відносний об'єм $V^{*} \epsilon$ важливим показником компактності теплоутилізаційного устаткування. Значення показника $V^{*}$ набуває особливого значення за умови обмежених площ котелень i має враховуватися під час проектування систем теплоутилізації.

Стосовно конструкційних характеристик теплообмінних поверхонь, то для водогрійних теплоутилізаторів як традиційні поверхні розглядали пучки гладких і плоскоовальних оребрених труб із нержавіючої сталі, а також пучки оребрених біметалевих труб (зі сталевою основою $з$ вуглецевої сталі та алюмінієвим оребренням). У разі застосування полімерних композитів при розгляді використовували гладкотрубні пучки.

Для вказаних пучків внутрішній діаметр труб приймали 25 мм, товщину стінок труб сталевих та 3 полімерних композитів - 3,5 мм. Висота оребрення із алюмінію становила $11 \mathrm{Mм}$, а міжреберний крок 3,5 мм. Геометричні параметри плоскоовальних труб приймали згідно з даними (Pismenny, 2007).

Композит, необхідний для водогрійного теплоутилізатора, вибирали, по-перше, зважаючи на те, що максимальна температура експлуатації робочої поверхні не має перевищувати значення найбільшої температури стінки теплообмінної поверхні, i, по-друге, коефіцієнт теплопровідності цих матеріалів повинен визначатися згідно з вимогами щодо необхідних значень теплопровідності таких поверхонь.

Щодо застосовуваних полімерних композитів, то їхні коефіцієнти теплопровідності змінювались під час розрахунків у діапазоні $0,2-30 \mathrm{BT} /(\mathrm{M} \cdot \mathrm{K})$. Перше з вказаних значень відповідає коефіцієнту теплопровідності ненаповненої полімерної матриці, друге - нержавіючої сталі.

Результати дослідження. Характерні результати виконаних досліджень наведено на рис. 2, що ілюструє залежність питомої теплопродуктивності та відносного об'єму водогрійних теплоутилізаторів від режиму роботи котла впродовж періоду опалення відповідно до температур навколишнього середовища $-20-+10^{\circ} \mathrm{C}$.

Як видно з рис. 2, а, характер залежності $Q^{*}=f\left(t_{\text {нс }}\right)$ має спільні особливості для всіх розглянутих типів водогрійних теплоутилізаторів. А саме, 3 підвищенням $t_{\text {нс }}$ від -20 до $-5{ }^{\circ} \mathrm{C}$ величина $Q^{*}$ зменшується, що зумовлено зниженням навантаження котла до $50 \%$. За $t_{\text {нс }} \approx-$ $5{ }^{\circ} \mathrm{C}$ різко зростає питома теплопродуктивність теплоутилізаторів завдяки переводу котла в номінальний режим роботи і відповідному зростанню витрати і температури димових газів на вході в теплоутилізатор. Подальше підвищення температури $t_{\text {нс }}$ призводить до зниження величини $Q^{*}$ через зменшення навантаження котла. Варто зазначити, що інтенсивність вказаного зниження $Q^{*}$ істотно відрізняється для різних типів утилізаторів. 

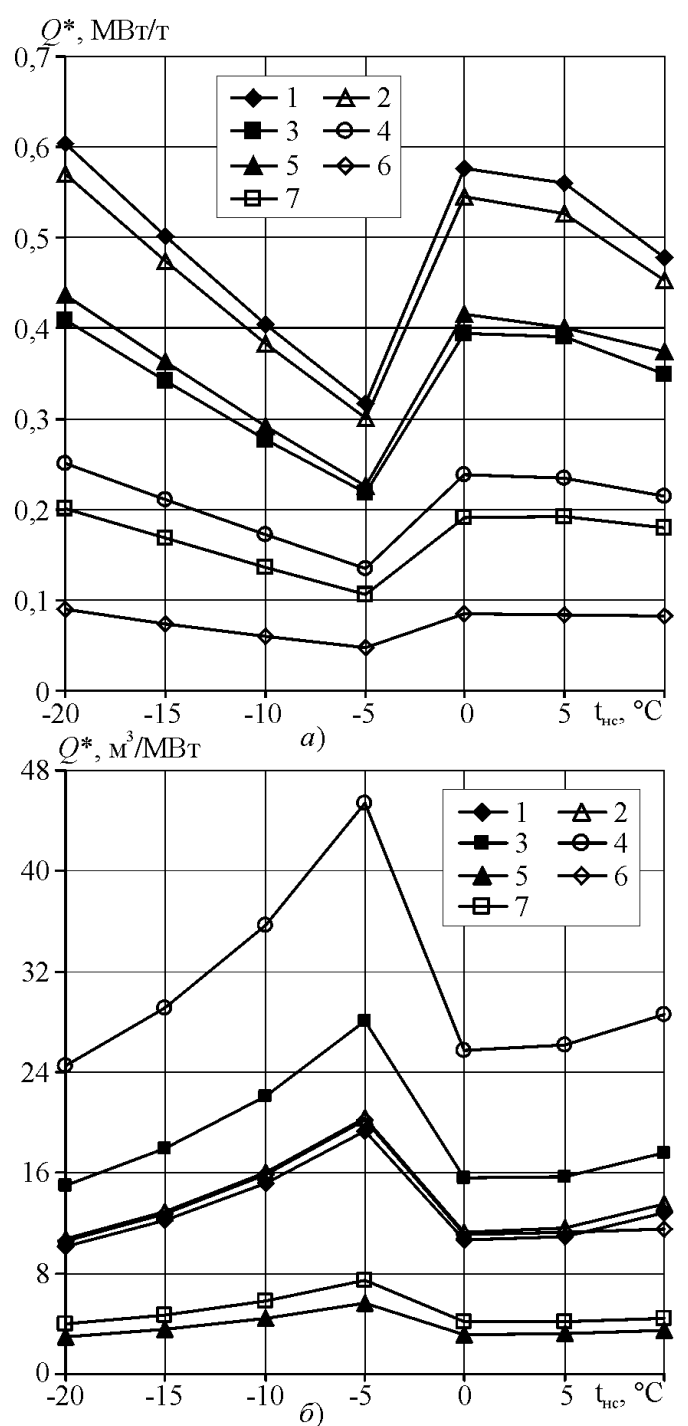

Рис. 2. Залежність питомої теплопродуктивності Q* (а) та відносного об'єму $\mathrm{V}^{*}$ (б) водонагрівача від температури навко-

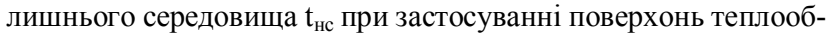
міну з різними пучками труб: $1-3)$ із нанокомпозитів $(\lambda=30,5$, $1 \mathrm{BT} /(\mathrm{м} \cdot \mathrm{K})) ; 4)$ із ненаповненого полімеру $(\lambda=0,2 \mathrm{BT} /(\mathrm{м} \cdot \mathrm{K}))$; $5)$ біметалевих оребрених труб $(\lambda=200 \mathrm{BT} /($ м $\cdot К)$ для алюмінію i $\lambda=40 \mathrm{Bт} /($ м $\cdot К)$ для вуглецевої сталі); 6,7$)$ гладких труб i плоскоовальних труб з оребренням із нержавіючої сталі $(\lambda=$ $30 \mathrm{BT} /($ м $\cdot$ К))

Як свідчать дані, наведені на рис. 2 (а), найбільші значення питомої теплопродуктивності $Q^{*}$ в усьому діапазоні зміни температури навколишнього середовища відповідають теплоутилізатору з полімерного композиційного матеріалу, коефіцієнт теплопровідності якого дорівнює $30 \mathrm{BT} /(\mathrm{M} \cdot \mathrm{K})$. Найнижчими значеннями $Q^{*}$ характеризуються теплоутилізатори, що компонуються гладкотрубними пучками 3 нержавіючої сталі. При цьому величини $Q^{*}$ для вказаних теплоутилізаторів відрізняються у 4-6 разів.

Привертає увагу той факт, що відмінності у значеннях питомої теплопродуктивності $Q^{*}$ для полімерних композитів з $\lambda=30 \mathrm{BT} /(\mathrm{M} \cdot \mathrm{K})$ та $5 \mathrm{BT} /(\mathrm{M} \cdot \mathrm{K}) \epsilon$ незначними і не перевищують 7 \%. Це пояснюють відносно невеликим термічним опором стінки теплоутилізатора 3 полімерного матеріалу порівняно 3 термічним опором тепловіддачі з боку димових газів.

Згідно з отриманими даними, питома теплопродуктивність $Q^{*}$ для теплоутилізаторів з усіх розглянутих полімерних композитів $(\lambda=30 ; 5 ; 1 \mathrm{BT} /(\mathrm{M} \cdot \mathrm{K}))$, врахову- ючи ненаповнений композит $(\lambda=0,2 \mathrm{BT} /($ м $\cdot \mathrm{K}) \epsilon$ вищою, ніж для теплоутилізаторів 3 нержавіючої сталі (гладкотрубні та оребрені пучки), що пов'язано з їі високою питомою вагою. Теплоутилізатори з біметалевих оребрених труб характеризуються істотно вищими значеннями $Q^{*}$, ніж теплоутилізатори $з$ нержавіючої сталі. Це зумовлено високою тепловою ефективністю біметалевих труб та їхньою меншою питомою вагою.

Отже, як показали проведені дослідження, за таким важливим показником теплової ефективності, як питома теплопродуктивність водогрійні теплоутилізатори 3 полімерних композитів мають істотні преваги над теплоутилізаторами з нержавіючої сталі.

На рис. 2 (б) наведено дані щодо відносного об'єму водогрійних теплоутилізаторів для різних температур навколишнього середовища. Ці залежності мають якісно однаковий характер для різних типів теплоутилізаторів. При цьому даний характер є протилежним тому, що має місце для залежності $Q^{*}=f\left(t_{\text {нс }}\right)$. Наведені дані свідчать про те, що найбільшою компактністю (найменшими значеннями $V^{*}$ ) характеризуються пучки біметалевих труб. Дещо поступаються їм за компактністю пучки із плоскоовальними трубами з нержавіючої сталі. Величини $V^{*}$ для гладкотрубних пучків 3 нержавіючої сталі та майже всіх розглянутих полімерних композитів відрізняються неістотно та приблизно в три рази перевищують відповідні значення для пучків біметалевих труб. Щодо пучків труб з ненаповненого полімеру, то вони є найбільш габаритними і менш компактними в 1,6-2,4 раза, ніж відповідні пучки з полімерних композитів.

За результатами виконаних досліджень можна зробити висновок, що водогрійні теплоутилізатори 3 полімерних композитів за компактністю поступаються теплоутилізаторам 3 оребрених труб. Цю обставину потрібно брати до уваги під час проектування теплоутилізаційних систем у котельнях, обмежених за площею.

Проведено також дослідження щодо визначення максимальної температури теплообмінної поверхні водонагрівача при компонуванні іï з полімерних мікро- i нанокомпозитів (рис. 3). Цю температуру, як відомо, потрібно враховувати у виборі складу композиту.

Як свідчать результати розрахунків (див. рис. 3), максимальні значення температури $t_{\text {пов }}^{\max }$ поверхні стінок водогрійних теплоутилізаторів $є$ відносно невисокими і близькими до температури нагріваної води. У діапазоні зміни температури димових газів у номінальному режимі $t_{\Gamma}^{\mathrm{H}}$ від 150 до $200^{\circ} \mathrm{C}$ вказані максимальні температури не перевищують $75^{\circ} \mathrm{C}$. Для всіх типів теплоутилізаторів 3 полімерних композитів наявне незначне зростання максимальної температури теплообмінної поверхні зі збільшенням рівня температур $t_{\Gamma}^{\mathrm{H}}$. 3 отриманих результатів досліджень максимальних температур стінок водогрійних теплоутилізаторів випливає, що матрицею для полімерних композитів може бути поліетилен з відносно низькою максимальною температурою експлуатації $\left(115^{\circ} \mathrm{C}\right)$. Щодо наповнювача цього полімеру, то для забезпечення відповідного коефіцієнта теплопровідності полімерного мікро- та нанокомпозиту можна застосовувати різні матеріали. В інституті розроблено типоряд полімерних мікро- і нанокомпозитів, призначених для застосування в теплоутилізаційному устаткуванні (Dolinsky, et al., 2015). 


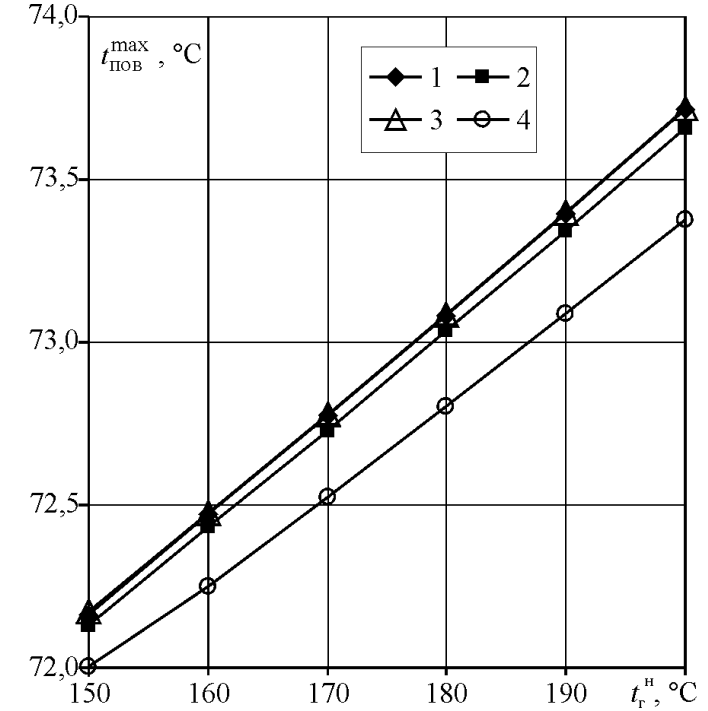

Рис. 3. Залежність максимальної температури $t_{\text {пов }}^{\max }$ поверхні теплообміну водонагрівача від температури $t_{\Gamma}^{\mathrm{H}}$ відхідних газів котла в номінальному режимі котла при застосуванні поверхонь теплообміну із нанокомпозитів з різними коефіцієнтами теплопровідності: $1-\lambda=30 \mathrm{BT} /(\mathrm{м} \cdot \mathrm{K}), 2-5 \mathrm{BT} /(\mathrm{м} \cdot \mathrm{K}), 3$ $1 \mathrm{BT} /(\mathrm{M} \cdot \mathrm{K}), 4-0,2 \mathrm{BT} /(\mathrm{M} \cdot \mathrm{K})$

Відповідно до цього типоряду в табл. наведено значення концентрацій різних наповнювачів (мікрочастинок алюмінію Al та вуглецевих нанотрубок ВНТ) для розглянутих у роботі значень теплопровідності теплообмінної поверхні водонагрівачів із мікро- та нанокомпозитів при застосуванні полімерною матрицею поліетилену (ПЕ).

Табл. Характеристики полімерних мікро- і нанокомпозитів для теплообмінних поверхонь водогрійного теплоутилізаційного устаткування

\begin{tabular}{|c|c|c|c|}
\hline $\begin{array}{c}\text { Теплопровід- } \\
\text { ність } \lambda, \text { Вт/(м·К) }\end{array}$ & $\begin{array}{c}\text { Тип полі- } \\
\text { меру }\end{array}$ & $\begin{array}{c}\text { Тип } \\
\text { наповнювача }\end{array}$ & $\begin{array}{c}\text { Частка } \\
\text { наповнювача, \% }\end{array}$ \\
\hline 1 & ПЕ & $\mathrm{Al}$ & 2,1 \\
\hline 5 & ПЕ & $\mathrm{Al}$ & 2,7 \\
\hline 10 & ПЕ & $\mathrm{Al}$ & 3,0 \\
\hline 20 & ПЕ & $\mathrm{Al}$ & 4,3 \\
\hline 25 & ПЕ & $\mathrm{BHT}$ & 3,2 \\
\hline 30 & ПЕ & $\mathrm{BHT}$ & 2,8 \\
\hline
\end{tabular}

\section{Висновки}

1. Виконано аналіз ефективності застосування полімерних мікро- і нанокомпозитів для теплообмінних поверхонь водогрійних теплоутилізаторів відхідних газів котельних установок за різних значень теплопровідності зазначених матеріалів.

2. Проведено зіставлення таких характеристик теплообмінних поверхонь, як теплопродуктивність $Q^{*}$ на одиницю маси теплообмінної поверхні та об'єм $V^{*}$ на одиницю їі теплопродуктивності для пропонованих теплоутилізаторів 3 нанокомпозиційних матеріалів і традиційних аналогів. Встановлено, що за питомою теплопродуктивністю $Q^{*}$ пропоновані теплоутилізатори перевищують аналоги 3 корозійностійкої сталі в 2-7 разів.

3. За значеннями робочих температур теплообмінної поверхні теплоутилізаторів 3 композиційних матеріалів показано, що полімерною матрицею для наповнення мікро- та нанокомпозитами може слугувати поліетилен.
Визначено необхідний склад наповнювачів для цієї матриці.

\section{Перелік використаних джерел}

Dinzhos, R. V., Fialko, N. M., \& Lysenkov, E. A. (2014). Analysis of the thermal conductivity of polymer nanocomposites filled with carbon nanotubes and carbon black. Journal of Nano-and Electronic Physics, 6(1), 1015, 1-6.

Dinzhos, R. V., Lisenkov, E. A., Fialko, N. M., \& Klepko, V. V. (2014). Vplyv metodu vvedennya napovnyuvacha na teplofizychni vlastyvosti system na osnovi termoplastychnykh polimeriv ta vuhletsevykh nanotrubok [Influence of the method of filling the filler on the thermophysical properties of systems based on thermoplastic polymers and carbon nanotubes]. Physical surface engineering, 12(4), 446-453. [in Ukraine].

Dolinskiy, A. A., Fialko, N. M., Dinzhos, R. V., \& Navrodskaya, R. A. (2015b). Teplofizicheskiye svoystva polimernykh mikro i nanokompozitov na osnove polikarbonata [Thermophysical properties of polymer microand nanocomposites based on polycarbonate]. Promyshlennaia teploehnika, 37(2), 12-19. [in Russian].

Dolinskiy, A. A., Fialko, N. M., Dinzhos, R. V., et al. (2015a). Teplofizicheskiye svoystva nizkoy teploprovodnosti polimernykh nanokompozitov dlya elementov energeticheskogo oborudovaniya [Thermophysical properties low thermal conductivity of polymer nanocomposites for the elements of power equipment]. Promyshlennaja teplotechnica, 37(6), 5-16. [in Russian].

Dolinsky, A. A., Fialko, N. M., Dinzhos, R. V., et al. (2015c), Teplofizicheskie harakteristiki vysokoteploprovodnyh polimernyh mikro- i nanokompozitov [Thermophysical characteristics of higt-conductivity polymeric micro- and nanocomposities]. Promyshlennaya teplotekhnika, 5, 5-14. [in Russian].

Dolinsky, A. A., Fialko, N. M., Navrodskaya, R. A., et al. (2014). Osnovnye printsipy sozdaniya teploutilizatsionnyh tehnologiy dlya kotelnyh maloy teploenergetiki [Basic principles of creating heat recovery technologies for small boilers houses power engineering]. Promyshlennaya teplotekhnika, 4, 27-36. [in Russian].

Fialko, N. M., Aronov, I. Z., Navrodskaya, R. A., et al. (2003), Effektivnost primeneniya kondensatsionnykh teploutilizatorov $\mathrm{v}$ sistemakh teplosnabzheniya [Efficiency of the use of condensation heat recovery units in heat supply systems]. Promyshlennaia teploehni$k a, 25(3), 36-41$. [in Russian].

Fialko, N. M., Gomon, V. I., Navrodskaya, R. A., et al. (2000). Osobennosti metodiki rascheta poverkhnostnykh teploutilizatorov kondensatsionnogo tipa [Peculiarities of the calculation procedure for surface heat exchangers of condensation type]. Promyshlennaia teploehnika, 22(2), 49-53. [in Russian].

Fialko, N. M., Navrodskaya, R. A., Shevuk, S. I., et al. (2014). Teplovyye metody zashchity gazootvodyashchikh traktov kotelnykh ustanovok s glubokim okhlazhdeniyem dymovykh gazov [Thermal methods for protecting gas exhaust ducts of boiler plants with deep cooling of flue gases]. Sovremennaya nauka: issledovaniya, idei, rezultaty, tekhnologii, 2, 13-17. [in Russian].

Kim, H., Bae, H., Han, Z., Yu, J., \& Kim, S. (2016). Thermal conductivity of polimer composites with the geomectrical characteristics of grapheme nanoplatelets. Scientific Reports, 6, 101-109.

Pismenny, E. N. (2007). Novye effektivnye razvitye poverkhnosti teploobmena dlya resheniia zadach energo- $\mathrm{i}$ resursosberezheniia [New effective developed heat exchange surfaces for solving energy and resource saving problems]. Promyshlennaya teplotehnika, 23(5), 7 16. [in Russian].

Zimin, L. B., \& Fialko, N. M. (2008). Analis effectivnosty yeplonasosnyh sistem utilizatsii teploty kanalizatsionnyh stokov dlia teplosnabzhenia sotsialnyh obektov [Analysis of the efficiency of heat pump systems for the utilization of heat of sewage for the heat supply of social facilities]. Promyshlennaia teplotehnika, 30(1), 7785. [in Russian]. 
${ }^{1}$ Институт технической теплофизики НАН Украины, г. Киев, Украина

\author{
${ }^{2}$ Николаевский наичональный университет им. В. А. Сухомлинского, г. Николаев, Украина
}

\title{
ВОДОГРЕЙНЫЕ КОНДЕНСАЦИОННЫЕ ТЕПЛОУТИЛИЗАТОРЫ С ПРИМЕНЕНИЕМ НАНОКОМПОЗИЦИОННЫХ МАТЕРИАЛОВ ДЛЯ ГАЗОПОТРЕБЛЯЮЩИХ ОТОПИТЕЛЬНЫХ КОТЛОВ
}

\begin{abstract}
Изложены результаты исследований эффективности использования в теплоутилизационных технологиях газопотребляющих отопительных котельных установок с глубоким охлаждением их отходящих газов водогрейного теплоутилизационного оборудования различного типа. Рассмотрено оборудование, теплообменные поверхности которого состояли из пучков поперечно-оребренных труб двух видов и гладкотрубных пучков. Определены для разных режимов работы котельных установок на протяжении отопительного периода такие относительные характеристики данных поверхностей, как теплопропризводительность на единицу массы этой поверхности и ее объем на единицу теплопропроизводительности. Выполнен сравнительный анализ указанных характеристик при использовании для поверхностей теплообмена традиционных материалов и полимерных микро- и нанокомпозитов с разными коэффициентами теплопроводности. По значению рабочих температур поверхности теплообмена из микро- и нанокомпозитов определена ее полимерная матрица, а по величине теплопроводности - необходимый состав наполнителей полимера, которыми могут служить микрочастицы алюминия или углеродные нанотрубки. Показано, что для отопительных котельных установок водогрейное теплоутилизационное оборудование из указанных нанокомпозиционных материалов по удельной теплопроизводительности имеет существенные преимущества над традиционными аналогами данного назначения.
\end{abstract}

Ключевые слова: теплоутилизационные технологи; глубокое охлаждение отходящих газов; полимерные микро- и нанокомпозиты; теплофизические свойства; эффективность.

\section{N. M. Fialko', R. O. Navrodska', R. V. Dinzhos ${ }^{2}$, S. I. Shevchuk ${ }^{1}$ \\ ${ }^{1}$ Institute of Engineering Thermophysics of NAS of Ukraine, Kyiv, Ukraine ${ }^{2}$ Mykolayiv National University named after V. O. Sukhomlynsky, Mykolayiv, Ukraine \\ HEATING CONDENSATION HEAT-OUTS WITH THE USE OF NANOCOMPOSITION MATERIALS FOR GAS-CONSUMING HEATING BOILERS}

The authors have presented the results of research on the efficiency of using gas-consuming heating boiler plants in deep heat recovery technologies with deep cooling of their waste gases of water-heating heat recovery equipment of various types. When carrying out the research, the traditionally used equipment was considered, the heat exchange surfaces of which consisted of bundles of smooth and cross-cut pipes of two types. In one of these types, bimetallic pipes (with a steel base and aluminium fins) were used, in the other flat-oval pipes with plate-shaped rectangular finning. As the surface material for these flat-oval pipes and smooth-tube bundles, alloy steel was used. The authors suggest using polymer micro- and nanocomposites as a material for the heat exchange surface for water heat recovery. In this case, these surfaces should be composed of bundles of smooth tubes. During the research for different operating modes of boiler plants during the heating period, such basic relative characteristics of these surfaces were determined, such as thermal permeability per unit mass of this surface and its volume per unit of heat capacity. A comparative analysis of these characteristics is made when using traditional heat exchange surfaces and surfaces made of polymeric micro- and nanocomposites with different heat conductivity coefficients for water heat recovery heaters. The value of the working temperatures of the heat transfer surface from micro- and nanocomposites is determined by its polymer matrix, and by the thermal conductivity the necessary composition of polymer fillers, which can be aluminium microparticles or carbon nanotubes. Thus, we have shown that in order to heat boiler plants, the hot-water heat recovery equipment of these nanocomposite materials by specific heat output has significant advantages over traditional analogues of this purpose.

Keywords: heat recovery technologies; deep cooling of waste gases; polymeric micro- and nanocomposites; thermophysical properties; efficiency. 